\title{
Base nacional: Uma reflexão a partir da representação social de professores(as) sobre a BNCC
}

\author{
National Base: A reflection from the social \\ representation of the teachers on the BNCC
}

Base nacional: Una reflexión a partir de la representación social de profesores sobre la BNCC

CAMILA RODRIGUES DOS SANTOS (10)

ELDA SILVA DO NASCIMENTO MELO (ib)

ERIVANIA MELO DE MORAIS (D)

\section{Resumo}

A Base Nacional Comum Curricular (BNCC) foi instituída com o objetivo de difundir conteúdos basilares para toda a Educação Básica brasileira, buscando o alcance da meta que prevê a aprendizagem com qualidade para as crianças de todo o país e a superação dos baixos índices nas avaliações nacionais e internacionais. Diante desse cenário, esse artigo traz debates de uma pesquisa quanti-qualitativa de abordagem psicossocial pautada na Teoria das Representações Sociais (TRS), realizada em 2019, tendo como objetivo refletir sobre a representação social que professores da rede básica de uma escola pública de ensino em Natal/Rio Grande do Norte têm sobre a BNCC. Por meio da estratégia metodológica da Técnica de Associação Livre de Palavra (TALP), buscou-se investigar os fios que entrelaçam as concepções desses professores(as), levantando as seguintes questões: Como esses

\footnotetext{
a Universidade Federal do Rio Grande do Norte (UFRN), Natal, RN, Brasil. Mestra em Educação, e-mail: mila.rodrigues.sts@gmail.com

b Universidade Federal do Rio Grande do Norte (UFRN), Natal, RN, Brasil. Doutora em Educação, e-mail: eldamelo@ufrnet.br

c Universidade Federal do Rio Grande do Norte (UFRN), Natal, RN, Brasil. Mestra em Educação, e-mail: moraiserivania@gmail.com
} 
professores(as) a partir das suas experiências com a docência, entendem a BNCC? Como está acontecendo a implementação da BNCC nas escolas de rede pública? É possível a partir da BNCC construir um currículo que combata as injustiças sociais e democratize a educação como um direito tal qual foi preconizado pela constituição de 1988? Os resultados encontrados contribuem para necessidade de construir formações pautadas no chão da história e nas realidades concretas da escola para elaboração de projetos pedagógicos curriculares.

Palavras-chave: Formação docente. Implementação. Política pública. BNCC. Representação Social.

\section{Abstract}

The Brazilian National Common Curriculum Base (BNCC) was established aiming the spreading of the basic contents to all the Brazilian Basic Education, seeking the achievement of the goal which predicts the quality learning for the children across the country and the overcoming of the low rates in national and international assessments. Considering this scenario, this paper discusses a quanti-qualitative research using a psychosocial approach based on the Theory of Social Representations (TSR), held in 2019, aiming to reflect on the social representation which the teachers of the basic network of a public school in Natal/Rio Grande do Norte have about the BNCC. Through the methodological strategy of the Free Word Association Technique (TALP), it was sought to investigate the threads which intertwine the conceptions of these teachers, raising the following questions: How do these teachers, from their experiences with teaching, understand the BNCC? How is the implementation of BNCC happening in public schools? Is it possible from the BNCC to build a curriculum which fights against the social injustices and democratizes the education as a right, as it is advocated by the 1988 constitution? The results of this research contribute to the need of building teacher trainings based on the ground of history and in the concrete realities of the school for the elaboration of curricular pedagogical projects.

Keywords: Teacher formation. Implementation. Public policy. BNCC. Social Representation.

\section{Resumen}

Se creó en Brasil la Base Nacional Común Curricular (BNCC) con el objetivo de difundir contenidos básicos para toda la Educación Básica brasileña, en busca el alcance de la meta que prevé el aprendizaje con calidad para los niños de todo el país y la superación de los índices bajos en las evaluaciones nacionales e internacionales. Delante de ese escenario, ese artículo trae debates de una investigación cuantitativa-cualitativa de enfoque psicosocial en la Teoría de las Representaciones Sociales (TRS), realizada en 2019, teniendo como objetivo reflexionar sobre la representación social que profesores de la educación básica de una escuela de la red pública de enseñanza en Natal/Rio Grande do Norte tienen la BNCC. Mediante de la estrategia metodológica de la Técnica 
de Asociación libre de Palabra (TALP), se buscó investigar los hilos que entrelazan las concepciones de esos profesores(as), planteando las siguientes preguntas: ¿Cómo es que estos profesores, a partir de sus experiencias con la docencia, entienden la BNCC? ¿Cómo se está implementando la BNCC en las escuelas públicas? ¿Es posible a partir de la BNCC construir un currículo que combata las injusticias sociales y democratice la educación como un derecho tal como fue defendido por la Constitución de 1988? Los resultados encontrados contribuyen a la necesidad de construir formaciones pautadas en el suelo de la historia y en las realidades concretas de la escuela para la elaboración de proyectos pedagógicos curriculares.

Palabras clave: Formación docente. Implementación. Política pública. BNCC. Representación Social.

\section{Introdução}

A Base Nacional Comum Curricular (BNCC) foi homologada por meio da Portaria n 1.570 de 20 de dezembro de 2017 (BRASIL, 2017b), pelo então Ministro da Educação Mendonça Filho, e instituída pela Resolução $\mathrm{CNE} / \mathrm{CP} \mathrm{n}^{\circ}$ 2, de 22 de dezembro de 2017 (BRASIL, 2017a), representando a preservação de uma concepção conservadora de sociedade. Diante desse contexto, a premência de consolidar uma educação para todos de forma universal e realizada com bases na equidade, na isonomia, com o acesso seria promovido democraticamente passa a ser um anseio distante da realidade social brasileira.

A Base foi construída com a intenção de diminuir as desigualdades no que tange às possibilidades de oportunizar um ensino cujo conhecimento não fosse diferenciado entre as diversas regiões do país, mas que permitisse o acesso de forma equânime. Para isso, foi planejado que a BNCC deveria ser implementada nas escolas até o final de 2018 e que no ano de 2019 os currículos das redes estaduais, municipais, sistemas de ensino das escolas, assim como, as práticas dos professores deveriam estar em consonância com o documento, sendo este contraditoriamente positivo e negativo para resolução dos problemas da educação, ou seja, as questões que envolvem o currículo são muitas vezes vistas como "responsáveis" pelo fracasso e ao mesmo tempo como a "salvação" dos dilemas educacionais e da desigualdade social.

Diante dessa complexificação que envolve a implementação da BNCC enquanto uma política educacional e pela necessidade de se realizar formações com os professores das redes pública e privada com o intento de que se construam novos 
currículos que tenham como orientação este documento, norteando as ações pedagógicas nas escolas, nos questionamos: Como esses professores(as), a partir das suas experiências com a docência, entendem a BNCC? Como está acontecendo a implementação da BNCC nas escolas da rede pública? É possível a partir da BNCC construir um currículo que combata injustiças sociais e democratize a educação como um direito tal qual foi preconizado pela constituição de 1988? São inquietações que iremos problematizar e refletir ao longo do texto.

Assim, este trabalho tem como objetivo geral refletir sobre a representação social que professores da rede básica de uma escola pública de ensino em Natal/Rio Grande do Norte têm sobre a BNCC. Tecemos como objetivos específicos: debater sobre a implementação da BNCC enquanto política pública nacional que busca a igualdade de acesso ao ensino; e analisar as representações sociais dos professores sobre a BNCC.

Para tanto, optamos por uma metodologia quanti-qualitativa, fundamentada em revisão bibliográfica e aplicação da Técnica de Associação Livre de Palavras, pois de acordo com Melo (2005), ao usar esta técnica o pesquisador estimula o participante da pesquisa a associar ideias e preencher espaços com palavras que serão pensadas pelos pesquisados ao entrarem em contato com um termo indutor que os faça acionar tais palavras. Posteriormente ao registro, ocorre a hierarquização das palavras, em que se deve enumerá-las em ordem crescente de importância e justificar a sua escolha, para que assim possam ser analisadas e interpretadas.

Como fundamento teórico-epistemológico, nos pautamos na Teoria das Representações sociais à luz de Moscovici (1978; 2010), que buscou em seus estudos refletir a sociedade e as relações sociais, baseado em uma abordagem psicossociológica, nos dando a possibilidade de apreendermos as perspectivas subjetivas construídas pelos sujeitos sociais coletivamente a partir de suas representações, que são como entidades quase tangíveis que circulam e se cristalizam em gestos, falas, encontros, concebidos no universo cotidiano (MOSCOVICI, 1978). Nossa escolha teórica está pautada na vertente da Escola Clássica, de Denise Jodelet, e na Escola de Aix-en-Provence, de Jean-Claude Abric e Claude Flament.

Portanto, vamos analisar e interpretar os dados obtidos através da aplicação da Técnica de Associação Livre de Palavras com os professores(as) realizada em 2019, 
com base na análise de conteúdo (BARDIN, 2011) que nos suscitou a formação de três campos semânticos denominados de "normativo"; "orientação da prática"; e "crítico", e também desenvolvemos um modelo analítico com fundamento na Teoria do Núcleo central (ABRIC, 1998) e na apresentação figurativa de "Espiral de Sentidos" (MELO, 2018; MORAIS, 2017; SANTOS, 2017), utilizada para proporcionar ao leitor uma proximidade com os elementos centrais, intermediários e periféricos, que são resultados do tratamento dos dados empíricos.

Com este foco, analisamos a política da educação básica no contexto da implementação obrigatória da BNCC nas escolas da rede pública e na relação dessas com a construção de um novo currículo. Em seguida, apresentamos as discussões e resultados da pesquisa, da análise do perfil dos sujeitos, dos campos semânticos e a espiral dos sentidos, construídos a partir da Técnica de Associação Livre de Palavras. Por fim, apresentamos considerações finais pautadas nos resultados obtidos na análise dos dados, em que reforçamos a relevância de se constituir um currículo balizado na participação coletiva e que possibilite a democratização do ensino.

\section{A implementação da BNCC: as escolas e a relação com um novo currículo}

A Base Nacional Comum Curricular (BNCC) para Educação Infantil e Ensino fundamental foi aprovada pelo Conselho Nacional de Educação (CNE) em dezembro de 2017. No entanto, a sua composição passou por um processo de muitas alterações na intenção de elaborar um documento de forma democrática. Santos e Morais (2019) apontam que tal organização teve início em 2015. Sendo um documento debatido nos sistemas de ensino nos Estados brasileiros, suas duas primeiras versões foram pautadas em uma construção democrática, assim "essa construção marca um momento histórico - pela primeira vez, uma política pública educacional era formulada a partir da visão do professor, aquele que está no "chão da escola"" (SANTOS; MORAIS, 2019, p. 16). Por outro lado, a terceira versão destoou da proposição inicial construída com a participação da sociedade civil.

O documento final entregue ao $\mathrm{CNE}$, apesar de ter sido levado a análises em Audiências Públicas, foi instituído verticalmente, se contrapondo às intenções 
democráticas de construção de uma Base Curricular que estivesse em sintonia com a diversidade e a pluralidade real da sociedade brasileira.

As discussões em torno da formulação de um documento curricular norteador não são recentes, assim, traçando uma linha histórica quanto à necessidade de se construir uma base curricular, encontramos sua primeira citação na promulgação da Constituição de 1988, no Artigo 210, que se legaliza a necessidade de que sejam "fixados conteúdos mínimos para o Ensino Fundamental, de maneira a assegurar formação básica comum e o respeito aos valores culturais e artísticos, nacionais e regionais" (BRASIL, 1988).

Na Lei no 9.394/1996, Lei de Diretrizes e Bases da Educação (LDB - BRASIL, 1996), encontra-se um outro avanço significativo para a educação, em que estabelece a inevitabilidade de um pacto interfederativo, ou seja, um acordo entre os diversos níveis de governo em que se estabeleçam competências e diretrizes capazes de orientar os currículos. Com as Diretrizes Curriculares Nacionais da Educação Básica (DCN) do ano 2013, no seu artigo 14, se concebe a necessidade de uma Base Nacional Comum com conhecimentos, saberes e valores produzidos culturalmente, expressos nas políticas públicas, os quais seriam gerados nas instituições produtoras do conhecimento científico e tecnológico.

Nas políticas públicas pautadas no Plano Nacional de Educação (PNE) no ano de 2014, reafirmou-se a necessidade de criar uma Base Nacional que orientasse a Educação Básica, com um currículo em todas as unidades da federação, assim deveria se buscar,

[...] estabelecer e implantar, mediante pactuação interfederativa [União, Estados, Distrito Federal e Municípios], diretrizes pedagógicas para a educação básica e a base nacional comum dos currículos, com direitos e objetivos de aprendizagem e desenvolvimento dos(as) alunos(as) para cada ano do Ensino Fundamental e Médio, respeitadas as diversidades regional, estadual e local (BRASIL, 2014).

Diante dessas discussões, bem como da necessidade de concretizar essa pactuação, ganhou destaque a formulação de uma BNCC que, de modo geral, buscou definir um conjunto de aprendizagens essenciais para orientar a educação em todo o país e que tivesse a participação da sociedade e sobretudo, daqueles que estão de fato diante da realidade do ensino nos estabelecimentos escolares em todas as regiões dos 
Estados, que são todos os profissionais da educação, professores, coordenadores, gestores, inspetores e comunidade em geral.

Entretanto, esse esforço democrático foi cessado a partir de 2016 com o impeachment de Dilma Rousseff, quando iniciou-se uma mudança no cenário político, que rebateu indubitavelmente nas políticas educacionais, inclusive na elaboração da BNCC, que passou a ser regulada por uma nova gestão, cujas bases se fundamentavam numa perspectiva privatista de concepções liberais e conservadoras, enfatizando a constituição da base com uma metodologia de construção linear, vertical e centralizadora.

Assim a Base, que buscou se constituir de forma democrática, passa a se impor verticalmente, de forma descompassada, compartimentalizando as etapas e não compreendendo a educação como um processo permanente e complexo, e isso pode ser observado com a construção da BNCC da Educação Infantil e Ensino Fundamental, deslocada da BNCC do Ensino Médio, a partir da instituição de uma Reforma cuja proposta tem início pela Medida Provisória (MP) n ${ }^{\circ}$ 746/2016, aprovada e transformada na Lei no 13.415, de fevereiro de 2017 (BRASIL, 2016; 2017), que foi orquestrada impositivamente para manter as sociabilidades dominantes. Nesse sentido, concordamos que,
A BNCC para a Educação Infantil e Ensino Fundamental, aprovada pelo CNE e homologada pelo MEC, apresenta-se, portanto, fragmentada, por excluir o Ensino Médio, e restritiva, à medida que direitos e objetivos de aprendizagem e desenvolvimento foram reduzidos a uma visão pedagógica centrada na aprendizagem, cuja materialização se expressa por meio de uma relação que subjuga o currículo à lógica da avaliação por desempenho. Tal concepção e política, de forte centralização e protagonismo do governo federal, não contribuem para o estabelecimento de políticas nacionais pautadas na relação de efetiva cooperação e colaboração entre os entes federativos, entre seus sistemas de ensino, instituições educativas, bem como seus profissionais e estudantes. (DOURADO; OLIVEIRA, 2018 p. 40).

A BNCC aprovada não reflete a manutenção e a preservação da democratização da educação e se coloca na contramão dos objetivos preconizados pela Constituição Federal de 1988 em seus artigos 205 e 206, que tratam a educação como um direito social fundamental, para o qual a colaboração de todos é imperativa (BRASIL, 1988), e das proposições refletidas pelo PNE 2014-2024 que tentam 
unificar os entes federados a um objetivo comum — a universalização da educação (BRASIL, 2014).

Antagonicamente a esse compromisso, a BNCC estrutura suas concepções político-pedagógicas opostas a perspectivas de um pluralismo que tem buscado o reconhecimento da diversidade cultural nacional, regional e local do país, dando lugar, segundo Dourado e Oliveira (2016, p. 41) “[...] a uma perspectiva de uniformização e homogeneização curricular, com a prescrição de currículo mínimo centrado em habilidades e competências [...]", que mantém regulado as estruturas pedagógicas, os conteúdos que devem ser ensinados e a não autonomia do professor que tem que seguir o que está sendo imposto. Assim,

Desde suas origens, o currículo tem se mostrado uma invenção reguladora do conteúdo e das práticas envolvidas nos processos de ensino e aprendizagem; ou seja, ele se comporta como um instrumento que tem a capacidade de estruturar a escolarização, a vida nos centros educacionais e as práticas pedagógicas, pois dispõe, transmite e impõe regras, normas e uma ordem que são determinadas. Esse instrumento e sua potencialidade se mostram por meio de seus usos e hábitos, do funcionamento da instituição escolar, na divisão do tempo, na especialização dos professores e, fundamentalmente, na organização da aprendizagem. (SACRISTÁN, 2013, p. 20)

Nesse sentido, a BNCC apesar do esforço inicial de uma composição curricular democrática, acaba por reafirmar essa perspectiva reguladora do ensino, que vai desaguar na escola e nas práticas pedagógicas dos professores que podem vir a reproduzir os pensamentos, as concepções de um determinado grupo, e por isso, esse currículo por ser constituído por orientações que não são isentas, sendo, pois, “[...] um território controverso e mesmo conflituoso a respeito do qual se tomam decisões [...]” (SACRISTÁN, 2013, p. 23), buscam atender a esse conjunto de ideias predominantes, levando a reprodução e a manutenção das estruturas dominantes.

Se não é fácil perceber simultaneamente a autonomia relativa do sistema de ensino e sua dependência relativa à estrutura das relações de classe, é porque, entre outras razões, a percepção das funções de classe do sistema de ensino está associada na tradição teórica a uma representação instrumentalista das relações entre a Escola e as classes dominantes, enquanto que a análise das características de estrutura e de funcionamento que o sistema de. ensino deve à sua função própria tem quase sempre tido por contrapartida a cegueira face às relações entre a Escola e as classes sociais, como se a comprovação da autonomia supusesse a ilusão da neutralidade do sistema de ensino (BOURDIEU; PASSERON, 1992, p. 204). 
A escola é o lugar por excelência em que os currículos serão postos em práticas a partir de um conjunto de elementos pedagógicos que promovam um processo que Bourdieu e Passeron (1992) denominaram como "inculcação cultural”. Este permite a manutenção das estruturas de classe e, portanto, são engendramentos quase que imperceptível no sistema, levando a uma percepção ou representação de que há neutralidades e que a escola é esse lugar que garante as formas de equidade e mobilidade social dos indivíduos, sendo que o contrário dessa perspectiva não é alcançada sobre a essência dos sistemas de ensino, de que "[...] ele é um dos fatores mais eficazes de conservação social, pois fornece a aparência da legitimação às desigualdades sociais, e sanciona uma herança cultural e o dom social tratado como dom natural" (BOURDIEU, 2015, p. 41).

Assim, pensar sobre a implementação da BNCC enquanto um currículo que oriente esses sistemas de ensino propõe, em primeiro lugar, compreender as distâncias sociais que podem ser evidenciadas com sua implantação; em segundo, entender que a BNCC precisa ser refletida a partir do contexto na qual foi produzida, para não apreendermos apenas as aparências e superficialidades do processo; e, por fim, pensar formações que suscitem aos professores(as) representações que os aproximem da realidade na qual se inserem, uma vez que, concordamos com Moscovici (2010) sobre pensar as representações como uma possibilidade de guiar para a ação e para a produção de uma outra práxis que não seja a manutenção da ordem dominante. Caso não busquem essas outras perspectivas de ações não será possível alcançar a democratização do ensino, muito menos combater as injustiças sociais, e essas continuarão a se perpetuar.

Quanto à implementação, destacamos que o documento da BNCC aponta uma nova organização curricular, partindo de dez competências gerais para Educação Básica. No Ensino Fundamental, apresenta uma disposição de áreas de conhecimento, sendo elas: área de Linguagens, área de Matemática, área de Ciências da Natureza, área de Ciências Humanas e área de Ensino Religioso, objetivando valorizar as situações lúdicas de aprendizagem, destacando a necessidade da articulação com as experiências vivenciadas na etapa anterior da Educação Infantil. Em seguida, são apresentadas competências específicas de cada ano nas diferentes áreas; a posteriori os componentes curriculares e as competências específicas de cada 
componente. Finaliza com a divisão de Anos Iniciais e Anos Finais para apresentação das unidades temáticas, dos objetivos de conhecimento e das habilidades a serem desenvolvidas.

Compreendendo essa mudança organizacional em relação aos Parâmetros Curriculares Nacionais $(\mathrm{PCN})$ - documento anterior a BNCC, referencial para construção dos currículos pelos sistemas de ensino e as propostas pedagógicas das instituições escolares — diante da nova abordagem, se fazem necessárias formações continuadas para os professores, coordenadores pedagógicos e gestores institucionais. Assim, a partir do ano 2018 a rede básica de ensino pública e privada do Brasil vivenciou momentos de apropriação, análise e aplicação do novo documento, a BNCC. O MEC, junto às Secretarias da Educação (Estaduais e Municipais), formulou uma série estratégias para essa implementação. Destacamos o Dia D — Dia Nacional de Discussão sobre a BNCC — um dia para debater a implementação da base, realizado no dia 6 de março de 2018. Os gestores e educadores foram convidados a promover estudos e debates sobre o texto final da BNCC. Para essa data a União Nacional dos Dirigentes Municipais de Educação (UNDIME), o Conselho Nacional de Secretários de Educação (CONSED) e o MEC sugeriram um conjunto de materiais com atividades, vídeos, temas, estratégias e apresentações para estimular o debate, que tinha como objetivo conhecer, refletir e entender a BNCC para posterior construção dos currículos e implementação nas escolas de todo o país.

A partir dessas reflexões e apontamentos, passamos para as análises, problematização e discussões dos resultados, considerando o que apreendemos sobre a representação social dos professores acerca da BNCC, demonstrada a partir da formação de campos semânticos e da espiral de sentidos.

\section{Discussões e resultados}

Antes de discutirmos os dados obtidos propriamente a partir da aplicação da Técnica de Associação Livre de Palavra (TALP) em julho de 2019, se coloca como relevante apresentarmos o perfil dos participantes da pesquisa, que nos trazem reflexões complexas sobre a Base e sobretudo sobre a formação docente. 
Os participantes foram dezessete professores(as) de uma escola da rede pública de ensino do município de Natal, Rio Grande do Norte, que atende a crianças da educação básica na etapa da Educação Infantil e Anos Iniciais do Ensino Fundamental. Eram 82,4\% mulheres e 17,6\% homens, dados que nos indicam a atuação expressiva da mulher pedagoga no contexto de educação de crianças.

Dos professores(as) que participaram da pesquisa, um tem entre 20 e 30 anos, um participante está na faixa etária entre 31 e 40 anos, oito entre 41 e 50 anos, seis têm entre 51 e 60 anos e um possui mais de 60 anos, demonstrando que são professores(as) com uma trajetória profissional de experiência na docência. Como podemos observar no Gráfico 1:

Gráfico 1 - Faixa etária dos participantes da pesquisa

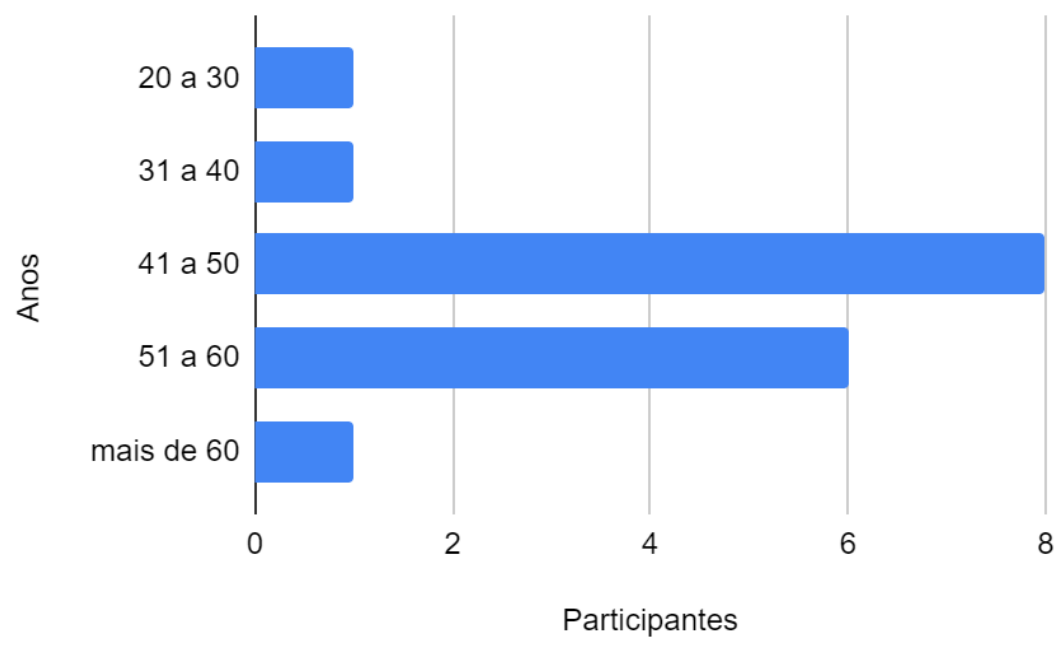

Fonte: Autoras (2020).

Ao longo de suas trajetórias os(as) professores(as) acumularam repertórios de conhecimentos e saberes que compõem as suas práticas, e esses saberes são decorrentes de perspectivas plurais, que segundo Tardif (2014) são instituídas pela formação profissional das ciências da educação e pedagógicas; pelos saberes disciplinares, que correspondem aos diversos campos de conhecimento de que dispõe a nossa sociedade; pelos saberes curriculares, que podem ser entendidos como norteadores de conteúdo, objetivos e etc.; e pelas experiências que são amalgamadas no tateamento da prática e incorporadas "à experiência individual e coletiva sob a 
forma de habitus e de habilidades do saber-fazer e de saber -ser". (TARDIF, 2014, p. 39). Assim, os participantes da pesquisa, são professores(as) que carregam uma trajetória profissional significativa, como demonstra o Gráfico 2.

Gráfico 2 - Experiência profissional dos participantes.

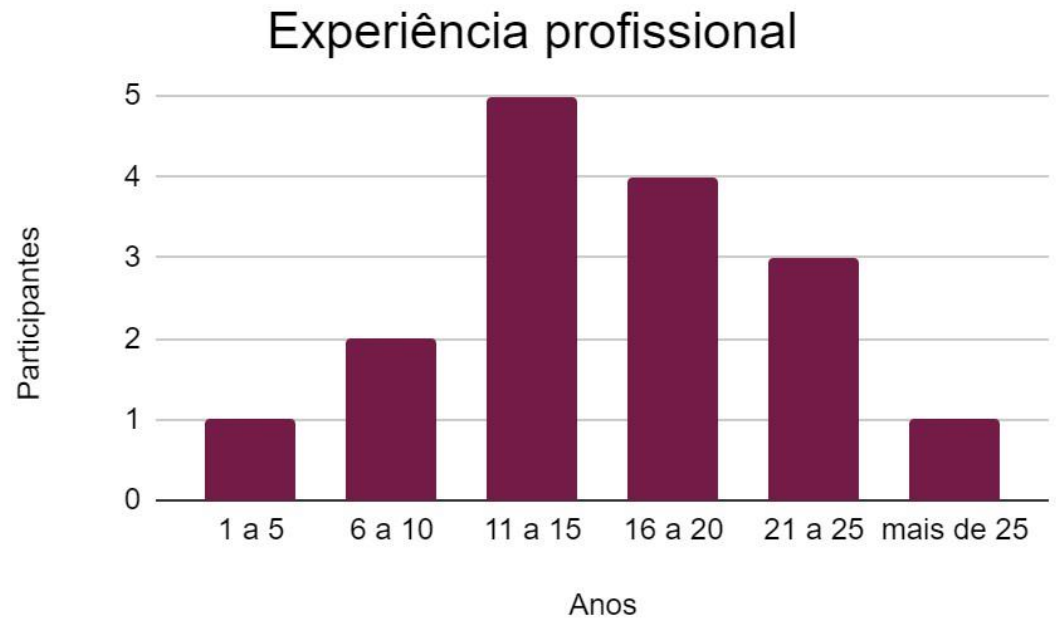

Fonte: Autoras (2020).

Destarte, é possível observar que um professor possui de 1 a 5 anos de experiência, dois de 6 a 10 anos, cinco de 11 a 15 anos, quatro entre 16 e 20 anos de prática, três participantes de 21 a 25 anos, um com mais de 25 anos e um dos professores não respondeu à questão relativa a essa informação, sendo um grupo com uma experiência profissional considerável. Desses, a maior parte são especialistas lato sensu, caracterizando 82\% dos entrevistados, que compreende a 14 professores; um professor tem mestrado em educação em uma universidade pública federal, compreendendo 5,9 \%, e apenas 2 possuem a formação docente inicial, pré-requisito para o cargo de professor Ensino Fundamental Anos Iniciais: a graduação com habilitação em licenciatura plena em Pedagogia, sinalizando 11,8\%, conforme demonstrado no Gráfico 3: 
Gráfico 3 - Formação dos participantes da pesquisa.

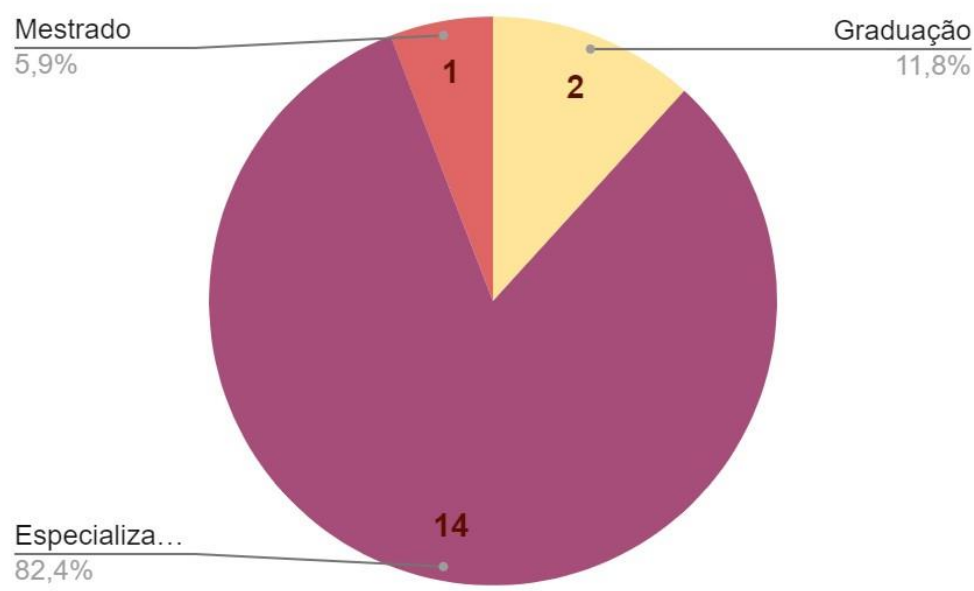

Fonte: Autoras (2020).

Esse grupo de professores(as) são profissionais que ao longo das suas experiências buscaram por novas formações, indicando um engajamento por conhecimentos que agreguem as suas respectivas práticas, enriquecendo a relação ensino-aprendizagem como elementos que se complementam e não se separam no processo formativo.

Devido à complexibilidade da profissão docente, a formação precisa ser entendida como permanente e deve estar para além de uma formação descontextualizada da realidade escolar. Nesse sentido "A formação deve levar em conta que, mais que atualizar o professor ou uma professora e ensiná-los, precisa criar as condições, planejar e propiciar ambientes para que ele ou ela aprendam" (IMBERNÓN, 2016, 145), e que essa aprendizagem esteja relacionada às diversas expressões sociais da realidade na qual se inserem.

Algumas dessas discussões serão revisitadas e ampliadas a partir da análise a seguir.

\section{Análise das representações: O que dizem os campos semânticos?}

A aplicação dos instrumentos de recolha de dados possibilitou acessar os principais elementos que conformam as representações sociais dos professores pesquisados nesse estudo. 
Na Tabela 1, podemos observar quantas evocações foram expressas pelos professores(as) participantes da pesquisa ao responderem a TALP, em seu primeiro contato com o termo indutor, ou seja: "BNCC é...". A partir desse termo obtivemos um total de 51 palavras, sendo 35 diferentes e 32 foram consideradas devido às aproximações semânticas, conforme demonstrado abaixo

Tabela 1 - Números: participantes e expressões evocadas.

\begin{tabular}{ll}
\hline Número dos participantes & 17 \\
\hline Número total de expressões evocadas & 51 \\
\hline Número de expressões diferentes evocadas & 35 \\
\hline Número de expressões diferentes consideradas & 32 \\
\hline
\end{tabular}

Fonte: Autoras (2020).

Considerando as palavras evocadas, foi possível criarmos campos semânticos que permitiram aproximações e reflexões sobre a representação social dos(as) professores(as) acerca da BNCC. Entretanto, é relevante salientarmos que a técnica de categorização, a partir de Bardin (2011), constitui-se em classificar os elementos de acordo com critérios possíveis de emergir sentidos, diante de ideias incipientes, porém, tais ideias não necessariamente expressam realidade totalizante, mas podem indicar uma aproximação analítica sobre o que esses professores pensam sobre a BNCC. Desse modo, no Quadro 1, apresentamos a interpretação semântica a partir das palavras analisadas. 
Quadro 1 - Quadro com as categorizações a partir das evocações

\begin{tabular}{|l|l|l|}
\hline \multicolumn{3}{|c|}{ CAMPOS SEMÂNTICOS } \\
\hline \multicolumn{1}{|c|}{ Normativa } & \multicolumn{1}{|c|}{$\begin{array}{c}\text { Orientação da } \\
\text { prática }\end{array}$} & \multicolumn{1}{c|}{ Crítica } \\
\hline Lei Nacional & Metodologia & Projeto neoliberal \\
\hline Direito & Direção & Imposição \\
\hline Norma & Organização & Adequação \\
\hline Proposta & Objeto & \\
\hline Educação & Escola & \\
\hline Reorganização & Meta & \\
\hline Normativo & Complemento & \\
\hline Orientação & Norte & \\
\hline Organização & esperança & \\
\hline Aprendizado & Base curricular & \\
\hline Foco & Planejamento & \\
\hline Sequência & Unificação & \\
\hline Fundamentação & Reavaliada & \\
\hline Necessidade & Conhecimento & \\
\hline
\end{tabular}

Fonte: Autoras (2020).

A partir das evocações, elucidamos três campos semânticos, que sinalizam de forma aproximativa como os(as) professores(as) da rede básica pública no ano de 2019 estavam compreendendo a BNCC, tendo em vista que esta deveria ter sido implementada nas escolas até o final de 2018. Nesse sentido, os currículos das escolas, assim como as práticas e os planejamentos, deveriam estar consonantes com o documento, o que tem se mostrado um propósito distante da realidade.

Ao analisarmos os dados observamos que, mesmo a escola tendo promovido o Dia D para os professores da instituição e com as formações continuadas da Secretaria Municipal de Educação, das quais os professores participam com frequência, doze professores(as), dos dezessete participantes da pesquisa, afirmam não terem participado de formações com temáticas relativas a BNCC até o final do primeiro semestre de 2019, data em que essa pesquisa foi realizada. Um número bem significativo, que demonstra a necessidade de se promover ações formativas que 
aproximem esses professores da BNCC, com estudos e discussões para que compreendam as dimensões políticas, sociais, econômicas e ideológicas que a norteiam, para que dessa forma não apenas reproduzam as concepções que orientam a base, mas que construam de forma autônoma um currículo que seja coeso com as suas respectivas realidades.

Assim, ao entrarem em contato com a afirmação a "BNCC é...", os professores(as) responderam as três primeiras palavras que pensavam sobre o documento em questão, e a partir dessas palavras aproximamos aquelas que semanticamente estavam relacionadas após analisarmos as justificativas dadas pelos participantes quanto a sua escolha pelas palavras. Dessas aproximações, chegamos a três campos: "Normativo"; "Orientação da prática" e "Crítico".

O campo denominado "Normativo", foi um dos mais expressivos, onde os participantes relacionaram as suas compreensões acerca da BNCC, como uma "Lei Nacional", "Direito", "Norma", entre outras palavras, que nos indicam uma representação formal e ligada a uma perspectiva de legalidade, como uma lei que deve orientar a organização das estruturas curriculares, das práticas e das escolas de forma verticalizadas, ou seja, cria-se uma lei de ensino e as demais instâncias devem seguir as orientações construídas.

Mas é importante salientarmos que nem sempre o que é instituído legalmente corresponde a um alcance da realidade. Pode-se, por exemplo, desenvolver formas de ensino que não atendem as especificidades de uma determinada localidade, por isso, precisa-se fazer uma reflexão pautada em fundamentos teóricos e amparados sob um ponto de vista legal, mas principalmente ancorado na realidade da comunidade escolar, considerando a necessidade de uma visão mais crítica quanto ao documento, no intuito de construir o Projeto Político Pedagógico da Escola, considerando a base, mas principalmente a realidade daquela comunidade escolar.

Outro campo expressivo foi o que intitulamos de "Orientação da Prática", em que as palavras evocadas tinham um sentido relacionado ao desenvolvimento da prática docente. Evocações como "Metodologia", "Direção”, “Organização”, entre outras, que sinalizavam que a BNCC seria um documento orientador das práticas desses professores(as) em exercício. 
Esses dois campos nos levam a reflexão que a BNCC é entendida como esse documento norteador das estruturas curriculares que devem ser seguidas pelas escolas, assim como, aquele que orientará as práticas. A palavra "Organização" nos traz essas duas perspectivas interpretativas: uma que leva ao campo "normativo" e outra como "orientação da prática”, como é possível apreender das justificativas dos(as) professores(as) ${ }^{1}$ com a evocação "organização":

Organizar as habilidades para que as competências relativas a cada segmento seja alcançada (Professor Participante 2).

A BNCC é um documento elaborado a partir de fundamentações teóricas sobre vários campos de desenvolvimento da formação básica, que servirá como norte das ações pedagógicas na escola, de forma que possibilite organização dessas ações e do currículo (Professor Participante 4).

É possível compreender a partir dessas justificativas que o sentido de “organização" evocado pelos participantes tinha essas duas direções, uma relacionada a um documento legal que estabelece habilidades e competências e outro que ordena a ações pedagógicas e do currículo na escola e que, portanto, auxiliam a prática docente. Nessa direção, deve ser o guia para ação citado por Moscovici (2010) ao tratar sobre a função das representações sociais.

Essas argumentações indicam uma aceitação quase incontestável do documento como sendo um manual para os professores de todo o país e que, se de fato seguirem essas orientações, teriam como resultado avanços na aprendizagem dos alunos, ou seja, não há nenhuma reflexão no que tange a compreensão da Base como um documento construído a partir de contradições e principalmente dentro de uma realidade diversificada culturalmente e socialmente como a do território brasileiro.

Essa apreciação foi possível situar nas evocações de um participante, que é aquele com a maior titulação, a de mestrado em educação, o que nos leva a reflexão de que uma formação fundamentada em perspectivas teóricas, mas também sem perder o lastro histórico social e da realidade nos possibilita uma compreensão mais ampla de contradições, das disputas hegemônicas existentes, construindo outras representações que constituam guias para ações críticas nas práticas docentes.

\footnotetext{
${ }^{1}$ No decorrer do texto iremos apresentar as falas dos participantes da pesquisa. 
Assim, o nosso quarto campo semântico denominamos de "crítico", em que surgiram as seguintes expressões "Projeto Neoliberal", "Imposição", "Adequação". Um dos participantes justifica as palavras, afirmando que "A política neoliberal impõe um currículo rígido para adequar a escola ao modo de produção capitalista" (Professor participante 17).

Este entendimento crítico que este participante possui nos chama atenção, ao pensar no deslocamento de um diálogo dentro da realidade escolar, havendo descompassos na inexistência de fundamentos teóricos que se relacionem com a leitura da realidade, podendo-se perceber a falta ou mesmo uma presença estreita de,

posturas críticas sobre temas como neoliberalismo, os efeitos da ação do Banco Mundial na política educacional, a privatização do ensino, a municipalização do ensino fundamental, a "autonomia" escolar, ou a organização da escolaridade em ciclo. O neoliberalismo, por exemplo, é visto por grande parte dos educadores escolares muita mais a partir de slogans, não percebendo, entre outros aspectos, como a defesa das leis "naturais" do mercado se coloca contra a própria especificidade do trabalho pedagógico, com consequências determinantes sobre as ações dos educadores em sala de aula (PARO, 2001, p. 29-30).

Paro (2001) ao analisar as políticas educacionais nos traz essa reflexão e nos coloca frente a provocações de que a formação docente precisa estar primeiro essencialmente relacionada a uma formação teórica rígida, segundo, apoiada nas discussões que nos permitam compreender o chão da história e, terceiro, fundamentada na realidade tangível, ou seja, nos conflitos, nas contradições, nas complexificações da escola e da sociedade.

Em seguida vamos apontar algumas considerações reflexivas sobre a interpretação dos dados a partir da espiral de sentidos, onde apresentaremos uma discussão das representações sociais dos professores(as) acerca da BNCC relacionadas ao conhecimento do próprio embasamento da abordagem estrutural e da Teoria das Representações sociais à luz de Moscovici (1978; 2010). 


\section{A espiral de sentidos como apresentação figurativa das representações sociais de professores(as) acerca da BNCC}

A Teoria do Núcleo Central (ABRIC, 1998) é uma das possibilidades de análise das representações sociais. A partir desta teoria e das formulações de Melo (2018) as palavras evocadas pelos participantes foram organizadas e demonstradas em forma de diagrama esférico - a espiral de sentidos. Essa apresentação dos dados está associada à visão celular, em que no centro estariam os elementos mais rígidos, mais compartilhados pelo grupo e as esferas adjacentes demonstram os elementos, intermediários e periféricos, que estão em processo de aproximação ou distanciamento do núcleo central. De acordo com Santos (2017) esses elementos estariam em constante movimento, a depender do compartilhamento de novos conhecimentos no âmbito do grupo ao qual os sujeitos pertencem.

A espiral de sentido nos permite uma melhor visibilidade do conteúdo representacional, tornando mais acessível a compreensão de sua dinâmica interna. Essa proposição de apresentação figurativa está pautada nas pesquisas para apresentação do Núcleo Central, proposta por Vergès (1992). A apresentação em forma de espiral vem sendo desenvolvida pelo grupo de pesquisa Educação e Representações Sociais, vinculado a linha: "Educação, Representações e Formação Docente" do Programa de Pós-Graduação da Universidade Federal do Rio Grande do Norte, desde 2015, em trabalhos com temáticas relativas a representação social e formação docente.

$\mathrm{Na}$ Figura 1 apresentamos a espiral de sentidos, desenvolvida a partir das análises das evocações dos(as) professores(as) sobre a BNCC. 
Figura 1 - Espiral de sentidos

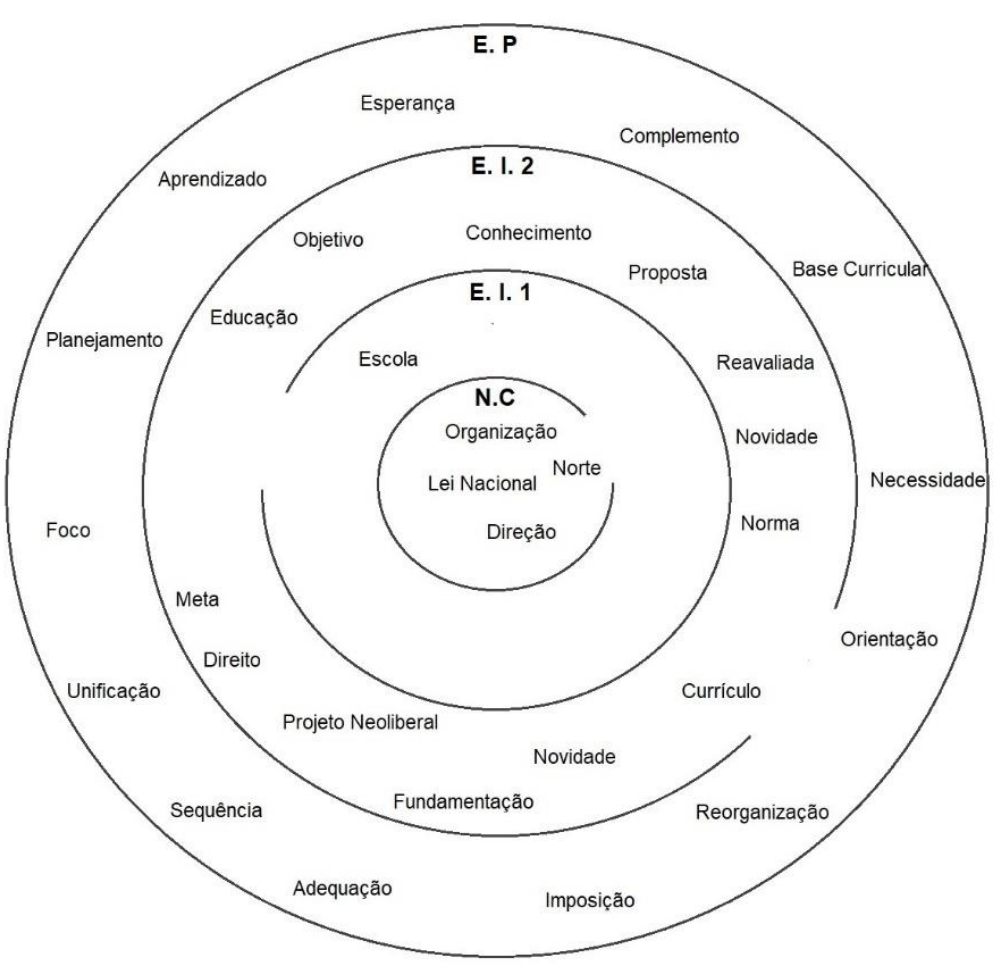

Fonte: Autoras (2020).

A partir da Figura 1, investigamos o núcleo central da representação social da BNCC, partilhada pelos(as) professores(as) da escola lócus da pesquisa, fundamentados nas análises dos dados auferidas na Técnica de Associação Livre de Palavras, por meio das evocações atribuídas ao termo indutor "BNCC é...". Partindo das evocações conhecemos as palavras referentes ao núcleo central, elementos intermediários e periféricos.

O núcleo central concebe os traços da memória coletiva do grupo que segundo Moscovici (2010) são partilhadas e penetram na mente de cada um, levando a uma ressignificação do objeto representado, no caso deste estudo, a BNCC. Assim, podemos inferir sobre os resultados, apontando as justificativas para a escolha dos termos e da sua contextualização teórica.

Apresentamos, pois, os elementos evocados nas respectivas esferas da estrutura. Consideramos todas as 51 evocações nessa análise, uma vez que cada sujeito menciona as três palavras que lhe vem à mente relativas ao termo indutor. O Núcleo Central (NC) está no círculo mais interno, composto pelos elementos: Lei nacional, organização, direção e norte. Essa formação de elementos se caracteriza a partir 
das condições históricas, sociais e ideológicas; o núcleo se qualifica por ser mais estável à mudança, por serem os elementos mais hegemonicamente compartilhados.

Nessa perspectiva, as representações sociais constituem uma forma de saber para compreender, analisar e conhecer um determinado fenômeno social. Destacamos que, partindo das comprovações apresentadas, percebemos em nosso núcleo central uma visão relativa a normatização, o que demonstra para os(as) professores(as) uma BNCC consubstanciada em uma Lei nacional, que organiza e direciona os currículos das instituições de ensino, e portanto é a partir dessa representação normativa que os professores organizam suas práticas pedagógicas. É possível compreender melhor a estruturação desse núcleo nas justificativas a seguir:

Acredito que a BNCC deve ser uma lei de melhorias, com projetos para a educação. (Professor participante 09);

Direção - Um documento que direciona o ensino brasileiro; Lei nacional - um documento; Organização - são direcionamentos organizado e sistematizado do ensino. (Professor Participante 15);

Direção: Que escolhas (conteúdos) precisam ser tomadas para alcançar as metas. (Professor Participante 14).

De acordo com a fala dos(as) professores(as), observamos que grande parte do grupo considera a necessidade de uma normatização, como apontado anteriormente em nossa análise semântica referente ao "Campo Normativo", que indica a BNCC como um caminho ou uma direção a ser seguida e que, portanto, as problemáticas da escola e das práticas seriam substanciadas.

A Base Nacional Comum Curricular (BNCC) é um documento de caráter normativo que define o conjunto orgânico e progressivo de aprendizagens essenciais que todos os alunos devem desenvolver ao longo das etapas e modalidades da Educação Básica, de modo a que tenham assegurados seus direitos de aprendizagem e desenvolvimento em conformidade com o que preceitua o Plano Nacional de Educação (PNE) (BRASIL, 2017, p. 7).

O próprio documento da base aponta para seu teor normativo e direcionável quando define o conjunto orgânico de aprendizagens essenciais necessário para o desenvolvimento de todos os alunos. No Brasil temos uma detalhada normatização curricular, em que diretrizes, parâmetros, orientações, referências municipais e 
estaduais são elaboradas por órgãos oficiais e circulam com significativa força, sendo essas bases fundantes para a construção dos currículos nas instituições de ensino.

Assim a constituição de um currículo não pode se centrar unicamente nos documentos. Como nos aponta Lopes (2018), sua base também está nos livros didáticos e literatura educacional, na formação inicial e continuada de professores, a partir das avaliações centralizadas, de projetos em parcerias entre Universidades e Escolas; são tantas as ações que integram o que a autora denomina de tradições curriculares.

$\mathrm{Na}$ segunda esfera, encontram-se os elementos mais próximos ao núcleo central, a Esfera Intermediária I (EI. I), com o elemento Escola. Um dos participantes da pesquisa utiliza essa evocação e justifica nessa escolha a "Escola lugar de formação para o crescimento dos sujeitos em todos os aspectos da vida humana; lugar de reflexão" (Professor Participante 06). Isso nos leva a refletir acerca da relevância de se reinventar a escola como espaço de sociabilidades e aprendizagens diversas. Nesse sentido podemos compreender que,

A escola assim concebida é um espaço de busca, de construção, diálogo e confronto, prazer, desafio, conquista de espaço, descoberta de diferentes possibilidades de expressão e linguagens, aventura, organização cidadã, afirmação da dimensão ética e política de todo o processo educativo. (CANDAU, 2013, p. 15)

Refletir sobre os principais conceitos e concepções sobre escola na ótica das representações sociais nos faz pensar além dessa perspectiva reprodutivista da escola, como salientam Bourdieu (2015) e Bourdieu e Passeron (1992). Evidenciamos, a partir de Jodelet (1985), que as características das representações sociais estão ligadas à prática discursiva dos sujeitos numa dada sociedade, uma vez que "Os processos comunicativos podem apreender o modo como, por meio da socialização, da educação, das trocas sociais e do compartilhamento de experiências, os sujeitos vão construir sua identidade e sua realidade comum" (JODELET, 2015, p. 321). Portanto, o sujeito passa a produzir uma representação quando reflete o que está fixo e/ou ideologicamente aceito, a partir do lugar que ocupa na sociedade. Assim, observamos a complexidade de análise da escola enquanto um espaço cujas representações sociais são constituídas por grupos que a valorizam e outros que a depreciam, desconsiderando seu lugar social de emancipação e democratização. 
Lopes (2018) ressalta que afirmar o valor da BNCC significa compreender a escola como carente de algo, realizando uma homogeneização das escolas como lugares onde não se ensina, em que não é problematizado o que se entende por currículo comum e o que se entende por conhecimento comum, considerando elementos que sustentem uma afirmação genérica e taxativa, da igualdade entre todos os estudantes e escolas, "de que alunas e alunos não aprendem na escola, desqualificando tudo que se realiza, desempoderando quem realiza” (LOPES, 2018, p. 25).

$\mathrm{Na}$ Esfera Intermediária II (EI. II) temos as evocações: novidade, direito, fundamentação, norma, reavaliada, conhecimento, proposta, objetivo, educação, meta, projeto neoliberal, currículo. Esses elementos, quanto mais próximos do núcleo central, seriam os que mais sofrem a influência dele. $\mathrm{Na}$ análise das justificativas, destacamos que esses elementos de fato enaltecem a função normativa em afirmações que são reiteradas para a centralidade curricular representada pela BNCC e que reduzem o debate pedagógico relativo à construção dos currículos das instituições de ensino.

De fato uma série de outros fatores devem ser considerados para constituição de uma proposta de direitos e objetivos de aprendizagem e desenvolvimento, como apontados por Aguiar (2018, p. 19) — “a garantia dos princípios constitucionais de liberdade de aprender, ensinar, pesquisar e divulgar o pensamento, a arte e o saber, bem como o pluralismo de ideias e de concepções pedagógicas" —, para que dessa forma se garanta a democratização do acesso e permanência do estudante nas escolas, salientando o protagonismo dos alunos e de professores a partir de suas assimetrias regionais e sociais.

Apenas o elemento projeto neoliberal não coaduna com as demais evocações. Nessa perspectiva, um participante da pesquisa ressalta a compreensão sobre a influência da ideologia neoliberal nas políticas públicas educacionais, em que a educação está relacionada ao mercado e para funcionar a sua semelhança, deixando de lado o campo social e político. Essas políticas neoliberais no papel estratégico da educação enfatizam que as propostas educacionais passam a ser impregnadas pela ideologia neoliberal (CAMPOS; SOUZA JÚNIOR, 2011). 
Finalmente, na esfera mais afastada do NC, Esfera Periférica (EP), as evocações que constituem os elementos periféricos dessa representação são orientação, reorganização, necessária, imposição, base curricular, complemento, esperança, aprendizado, planejamento, foco, unificação, sequência e adequação. Esses elementos se configuram em uma estrutura que organiza a representação e compreensão do núcleo central. Os elementos periféricos, uma vez que são indispensáveis ao sistema central, por estarem articulados a uma interface entre a realidade concreta e o sistema central, funcionam exatamente como uma entidade em que cada parte tem um papel específico e complementar à outra parte (ABRIC, 1994 apud SÁ, 1996). Estes estão reforçando o núcleo central ao apresentarem elementos que reiteram o sentido de normatização, embora a palavra imposição contrarie essa ideia e se relacione com o campo semântico "crítica", analisado anteriormente neste estudo.

A função normatização, de acordo com Aguiar (2018), está relacionada com alguns profissionais da educação que acreditam nesse modelo em que cartilhas, guias como "receitas", a serem reproduzidos nas escolas, serão "remédio" infalível para os "males" da educação, desconsiderando o grande potencial de nossas comunidades educacionais e escolares. Podemos evidenciar tal compreensão em algumas justificativas, a exemplo desta a seguir.

A BNCC surge como uma diretriz (norma) após as mudanças sofridas no processo de elaboração, apesar de ter surgido de uma necessidade de integração curricular, mas continua como uma esperança de redirecionamento das atividades curriculares e pedagógicas nacional (Professor Participante 05).

Porém, de acordo com o delineado em dispositivos legais, como nas Diretrizes Curriculares Nacionais (DCN) para a Educação Básica, compreendemos que os profissionais da educação e estudantes devem ter assegurado seu protagonismo, para que possam atualizar e ressignificar saberes, fomentando o conhecimento social e sua relação com a realidade concreta.

A base seria um documento de discussão e análise crítica, pois nem todas as escolas das diferentes regiões do país precisam ter o mesmo currículo, uma vez que, este precisa fazer sentido para as instituições escolares nas suas respectivas realidades 
históricas e sociais e deve ser construído contextualmente considerando suas demandas e necessidades, que são heterogêneas.

\section{Considerações Finais}

As discussões em torno da Base Nacional Comum Curricular (BNCC) têm sido o centro de inúmeras reflexões e problematizações que buscam compreender a relevância de um currículo que alcance toda a sociedade. Assim, neste trabalho, buscamos trazer para o debate outras perspectivas analíticas de cunho crítico, não com o objetivo de esvaziar o debate, mas pelo contrário: nossa intenção foi a de provocar e pensar se esse documento, do jeito que foi elaborado e da forma como tem chegado aos professores, se aproxima dos objetivos e finalidades construídas pelo próprio documento, que é democratizar o ensino.

Assim, como vimos ao longo das reflexões, a BNCC foi um documento pensado desde a Constituição de 1988 e expresso também no Plano Nacional de Educação (PNE), como um objetivo que deveria ser um compromisso dos entes federados para se construir uma educação democrática e universal. Esse propósito iniciou-se em 2015 com as primeiras formulações, seguindo as prerrogativas de uma elaboração participativa, mas que foi interrompida em 2016. No final de 2017, no então governo de Michel Temer, a terceira e última versão é concebida de forma antidemocrática sem levar em consideração o que havia sido debatido anteriormente.

Nesse sentido, a BNCC deveria ter sido implementada nas instituições escolares no ano de 2018. Entretanto, não foi o que se efetivou, e em 2019, ano em que realizamos essa pesquisa, muitas escolas ainda não haviam construído seus projetos políticos pedagógicos ancorados na base e os docentes que deveriam teoricamente ter suas práticas fundamentadas nas propostas das escolas continuavam a seguir as "velhas cartilhas", e tampouco haviam participado de formações a respeito da BNCC, como analisamos.

Assim, para atender a essa demanda, em 2019 foi publicada a Resolução CNE/CP no 2, de 20 de dezembro de 2019, que define as Diretrizes Curriculares Nacionais para a Formação Inicial de Professores para a Educação Básica e institui a Base Nacional Comum para a Formação Inicial de Professores da Educação Básica 
(BNC-Formação), como uma possibilidade de ampliar o processo formativo dos(as) professores(as) de todo o território nacional, a fim de aproximá-los da BNCC enquanto política pública nacional. Entretanto, é importante destacar que uma formação não pode ser pautada apenas em perspectivas teóricas, mas deve levar em consideração o chão da história e a realidade social concreta da escola.

Desse modo, ao aprendermos a representação social dos(as) professores(as) acerca da BNCC, compreendemos uma representação pouco crítica, afastada da realidade concreta, em que o professor não percebe o seu protagonismo na análise e interpretação da base para construção de uma outra práxis que transforme a realidade. Há um processo de aceitação da BNCC em uma visão mais positivista, considerando seguir a base sem um debate crítico e reflexivo.

Destarte, através das análises realizadas, relativas aos campos semânticos, foi possível desvelar o campo "Normativo"; "Orientação da prática"; "Crítico". Nas análises da abordagem estrutural da espiral de sentidos, concluímos que a representação social para aquele grupo de professores(as), naquele determinado momento, está objetivada na BNCC como uma normatização para as práticas pedagógicas, levando-os a uma perspectiva não de autonomia, mas de anomia no processo de aprendizagem dos alunos. Ou seja, por seguir e valorizar o que está definido e regulamentado na base quanto às competências e habilidades, sem tecer críticas ou mesmo sem relacionar com a realidade na qual se inserem, os docentes se afastam de um processo criativo de construção de saberes coletivamente elaborados nas suas relações com o outro, que tem uma história, que traz um conhecimento, porque "Não há docência sem discência" (FREIRE, 2019, p. 25). Portanto, esse currículo precisa ser pensado e tanto levar em consideração os elementos objetivos que se expressam nas inúmeras dificuldades estruturais das escolas como também entender a complexidade de cada sujeito que compõe a comunidade escolar.

Nesse sentido, se faz necessário constituir processos formativos que permitam aos professores o uso do seu protagonismo na elaboração de propostas pedagógicas curriculares pautadas na realidade da escola, e que sejam realizadas de forma coletiva e participativa com toda a comunidade escolar, considerando os documentos oficiais como um suporte de análise para discussão crítica sobre os objetivos dos 
desenvolvimento e aprendizagem pautados nas singularidades, diversidades e pluralidades das crianças e da escola.

\section{Referências}

ABRIC, J.-C. A abordagem estrutural das representações sociais. In: MOREIRA, A. S. P.; OLIVEIRA, D. C. de (Orgs.). Estudos interdisciplinares de representação social. Goiânia: AB Editora, 1998. p. 27-38.

AGUIAR, M. A. da S. Relato da Resistência à Instituição da BNCC pelo Conselho Nacional de Educação Mediante pedido de vista e declaração de votos. In: AGUIAR, M. A. da S.; DOURADO, L. F. (Org.). A BNCC na contramão do PNE 2014-2024: avaliação e perspectivas. Recife: ANPAE, 2018. p. 8-22.

BARDIN, L. Análise de conteúdo. Trad. Luis Antero Reto; Augusto Pinheiro. São Paulo: Edições 70, 2011.

BOURDIEU, P.; PASSERON, J. C. A reprodução: Elementos para uma teoria do sistema de ensino. Rio de Janeiro: Francisco Alves, 1992.

BOURDIEU, P. A escola conservadora: as desigualdades frente à escola e à cultura. In: BOURDIEU, P. Escritos da Educação. Org. Maria Alice Nogueira; Afrânio Catani. 16. ed. Petropólis, RJ: Vozes, 2015. p. 43-72.

BRASIL. Ministério da Educação. Conselho Nacional de Educação. Base Nacional Comum Curricular. Resolução CNE/CP N² 2. Brasília, 2017a.

BRASIL. Constituição da República Federativa do Brasil. Brasilia, DF: Senado Federal, 1988. Disponível em: http://www.planalto.gov.br/ccivil_03/constituicao/constituicao.htm. Acesso em: 14 fev 2020.

BRASIL. Ministério de Educação e Cultura. LDB - Lei no 9394/96, de 20 de dezembro de 1996. Estabelece as diretrizes e bases da Educação Nacional. Brasília: MEC, 1996.

BRASIL. Plano Nacional de Educação (PNE) 2014-2024: Lei no 13.005, de 25 de junho de 2014. Brasília: Edições Câmara, 2014. (Série legislação, n. 125). Disponível em: http://www.observatoriodopne.org.br/uploads/reference/file/439/documentoreferencia.pdf. Acesso em: 12 fev. 2020.

BRASIL. Medida provisória $n^{\circ} 746$ de 2016. Diário Oficial [da] República Federativa do Brasil, Poder Executivo: Brasília, DF, 23 set. 2016. Edição Extra.

BRASIL. Ministério de Educação e Cultura. Portaria $\mathrm{n}^{\circ} 1570$, de 22 de dezembro de 2017b. Homologação da BNCC. Disponível em: http://basenacionalcomum.mec.gov.br/images/historico/PORTARIA1570DE22 DEDEZEMBRODE2017.pdf. Acesso em: 15 mai. 2020.

CAMPOS, F. A. C.; SOUZA JÚNIOR, H. P. Políticas públicas para a formação de professores: desafios atuais. Trabalho \& Educação, Belo Horizonte, v. 20, n. 1, p. 33-46, jan./abr. 2011. 
CANDAU, V. M. (Org.). Reinventar a Escola. Petrópolis, RJ: Vozes, 2013.

DOURADO, L. F.; OLIVEIRA, J. F. de. Base Nacional Comum Curricular (BNCC) e os impactos nas políticas de regulação e avaliação da educação superior. In: AGUIAR, M. A. da S.; DOURADO, L. F. A BNCC na contramão do PNE 2014-2024: avaliação e perspectivas. [Livro Eletrônico]. Recife: ANPAE, 2018. p. 38-43 Disponível em: https://www.anpae.org.br/BibliotecaVirtual/4-Publicacoes/BNCC-VERSAO-

FINAL.pdf. Acesso em: 14 mai. 2020.

FREIRE, P. Pedagogia da Autonomia: Saberes necessários à prática educativa. 59. ed. Rio de Janeiro/São Paulo: Paz e Terra, 2019.

IMBERNÓN, F. Qualidade do ensino e formação do professorado: uma mudança necessária. São Paulo: Cortez, 2016.

JODELET, D. Representações Sociais: fenômenos concepções e teoria. In: MOSCOVICI, Serge. Psicologia Social, 1985.

JODELET, D. Problemáticas psicossociais da abordagem da noção de sujeito. Cadernos de Pesquisa, v. 45, n. 156, p. 314-327, abr./jun. 2015. Disponível em: https://www.scielo.br/pdf/cp/v45n156/1980-5314-cp-45-156-00314.pdf. Acesso em: 15 mai. 2020.

LOPES, A. C. Apostando na produção contextual do currículo. In: AGUIAR, M. A. da S.; DOURADO, L. F. (Org.) A BNCC na contramão do PNE 2014-2024: avaliação e perspectivas. Recife: ANPAE, 2018. p. 23-27.

MELO, E. S. do N. Campo Educacional e representação social da formação docente: o olhar dos agentes. Orientador: Moisés Domingos Sobrinho. 2005. 141 f. Dissertação (Mestrado em Educação) - Centro de Ciências Sociais Aplicadas, Universidade Federal do Rio Grande do Norte, Natal, 2005.

MELO, E. S. do N. Espiral de sentidos: Representação Social de estagiários do curso de licenciatura em Ciências Sociais sobre formação de professores. In: CONFERÊNCIA INTERNACIONAL SOBRE REPRESENTAÇÕES SOCIAIS, 14., 2018, Buenos Aires. 2018.

MORAIS, E. M. de. Representação social e Docência: um estudo sobre a formação de licenciandos da UFRN (campus central) a partir do Programa Institucional de Bolsa de Iniciação à Docência (PIBID). Orientadora: Elda Silva do Nascimento Melo. 2017. 221 f. Dissertação (Mestrado em Educação) - Centro de Educação, Universidade Federal do Rio Grande do Norte, Natal, 2017.

MOSCOVICI, S. A representação social da psicanálise. Rio de Janeiro: Zahar, 1978.

MOSCOVICI, S. Representações sociais: Investigações em Psicologia Social. 9. ed. Petrópolis, RJ: Vozes, 2010.

PARO, V. H. Políticas Educacionais: considerações sobre o discurso genérico e a abstração da realidade. In: DOURADO, L. F.; PARO, V. H. Políticas Públicas \& Educaşão Básica: São Paulo: Xamã, 2001. p. 29-47.

SÁ, C. P de. Núcleo central das representações sociais. Petrópolis: Vozes, 1996. 
SACRISTÁN, J. G. O que significa o currículo?. In: SACRISTÁN, J. G. (Org.). Saberes e incertezas sobre o currículo. Porto Alegre: Penso, 2013. p. 16-35.

SANTOS, C. R. As representações sociais sobre o Pacto Nacional pela Alfabetização na Idade Certa PNAIC: o olhar dos(as) professores(as) alfabetizadores(as) do município de Natal-RN. Orientadora: Elda Silva do Nascimento Melo. 2017. 260 f. Dissertação (Mestrado em Educação) - Centro de Educação, Universidade Federal do Rio Grande do Norte, Natal, 2017.

SANTOS. C. R.; MORAIS, E. M. BNCC: Fundamentos Epistemológicos para a Formação Docente. In: SANTOS, C. R.; SBRUSSI, M. P. B. P.; NEVES, V. L. S. (Org.). BNCC em debate: Como fica a docência? Curitiba: CRV, 2019. p. 15-32.

TARDIF, M. Saberes docentes e formação profissional. 17 ed. Petrópolis, RJ: VOZES, 2014.

VERGÈS, P. Conjunto de programas que permitem a análise de evocações: EVOC: manual. Versão 5. Aix en Provence: [s.n.], 2002. Disponível em: https://pucsp.br/pos/ped/rsee/evoc.htm. Acesso em: 01 dez. 2019.

RECEBIDO: $31 / 05 / 2020$

APROVADO: 04/12/2020
RECEIVED: 05/31/2020

APPROVED: $12 / 04 / 2020$
RECIBIDO: $31 / 05 / 2020$

APROBADO: 04/12/2020 